\title{
Intake, status and dietary sources of riboflavin in a representative sample of Irish adults aged 18-90 years
}

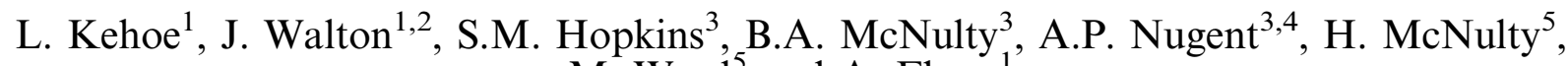 \\ M. Ward ${ }^{5}$ and A. Flynn ${ }^{1}$ \\ ${ }^{1}$ School of Food and Nutritional Sciences, University College Cork, Ireland, ${ }^{2}$ Dept. Biological Sciences, Cork Institute \\ of Technology, Ireland, ${ }^{3}$ UCD Institute of Food and Health, University College Dublin, Ireland, ${ }^{4}$ Institute for Global \\ Food Security, School of Biological Sciences, Queens University Belfast, Northern Ireland and ${ }^{5}$ Nutrition Innovation \\ Centre for Food and Health, Ulster University, Coleraine, Northern Ireland
}

Riboflavin is a water soluble B-vitamin which, in its coenzymatic forms flavin mononucleotide (FMN) and flavin adenine dinucleotide (FAD) is required for numerous oxidation/reduction reactions and plays an integral role in the metabolism of other B-vitamins and the related metabolite homocysteine. The objective of this study was to estimate the usual intake, prevalance of inadequate intakes, biochemical status and dietary sources of riboflavin in Irish adults using data from the National Adult Nutrition Survey (2008-2010) (www.iuna.net). A 4-day semi-weighed food record was used to collect food and beverage intake data from a representative sample of

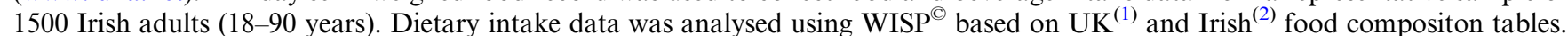
Blood samples $(n$ 1126) were collected, processed and analysed using stardard operating procedures. Usual intakes were calculated via the NCI-method ${ }^{(3)}$ using SAS ${ }^{\odot}$ Enterprise Guide. The estimated average requirement (EAR) of $1.3 \mathrm{mg} / \mathrm{d}$ (for adults $\geq 18$ years) established by the European Food Safety Authority ${ }^{(4)}$ was used as a cut-off to assess the prevalence of inadequate intakes (excluding energy-underreporters). Determination of riboflavin biomarker status was by erythrocyte glutathione reductase activation coefficient (EGRac), calculated as the ratio of flavin-dependent glutathione reductase activity before and after in vitro reactivation with its prosthetic group FAD, with a cut-off value of $>1 \cdot 3$ generally used to indicate low/deficient status ${ }^{(5)}$.

Table 1. Prevalence of low/deficient riboflavin intakes/biomarker status and key dietary sources of riboflavin

\begin{tabular}{|c|c|c|c|c|c|c|c|c|}
\hline \multirow{2}{*}{ Age (years) } & \multicolumn{2}{|c|}{$18-35$} & \multicolumn{2}{|c|}{$\begin{array}{r}36-50 \\
\end{array}$} & \multicolumn{2}{|c|}{$51-64$} & \multicolumn{2}{|c|}{$65+$} \\
\hline & Males (n 276) & Females $(n 255)$ & Males (n 205) & Females (n 232) & Males ( $n$ 153) & Females $(n 153)$ & Males (n 106) & Females $(n 120)$ \\
\hline \multicolumn{9}{|c|}{ Low/deficient riboflavin intakes/biomarker status } \\
\hline$\%$ with intakes $<$ EAR & 9.9 & $21 \cdot 2$ & $14 \cdot 5$ & $25 \cdot 6$ & $14 \cdot 9$ & $19 \cdot 6$ & $25 \cdot 1$ & $19 \cdot 4$ \\
\hline$\%$ with EGRac $>1 \cdot 3$ & $62 \cdot 9$ & $70 \cdot 1$ & $58 \cdot 3$ & $63 \cdot 8$ & $53 \cdot 1$ & $57 \cdot 8$ & $54 \cdot 5$ & $50 \cdot 6$ \\
\hline \multicolumn{9}{|c|}{ Contribution (\%) of food groups to intakes of riboflavin } \\
\hline Milks & $21 \cdot 0$ & $19 \cdot 7$ & $23 \cdot 2$ & $22 \cdot 4$ & $22 \cdot 7$ & $19 \cdot 4$ & $20 \cdot 7$ & $23 \cdot 7$ \\
\hline Meat \& meat products & $16 \cdot 5$ & $14 \cdot 2$ & 18.4 & $14 \cdot 5$ & $17 \cdot 1$ & $15 \cdot 1$ & $17 \cdot 7$ & $14 \cdot 7$ \\
\hline $\begin{array}{l}\text { Ready-to-eat breakfast } \\
\text { cereals }\end{array}$ & $13 \cdot 8$ & $12 \cdot 5$ & $12 \cdot 7$ & $11 \cdot 9$ & $9 \cdot 4$ & $8 \cdot 5$ & $5 \cdot 9$ & $10 \cdot 2$ \\
\hline Beverages & $10 \cdot 2$ & $6 \cdot 7$ & $10 \cdot 0$ & $8 \cdot 7$ & $12 \cdot 3$ & $7 \cdot 7$ & $11 \cdot 3$ & $7 \cdot 8$ \\
\hline Tea & $1 \cdot 7$ & $3 \cdot 7$ & $4 \cdot 1$ & $6 \cdot 4$ & $6 \cdot 4$ & $6 \cdot 3$ & $7 \cdot 0$ & $6 \cdot 8$ \\
\hline Alcoholic beverages & $8 \cdot 3$ & $2 \cdot 6$ & $5 \cdot 5$ & 1.9 & $5 \cdot 7$ & 1.0 & $4 \cdot 0$ & $0 \cdot 3$ \\
\hline Other beverages & $0 \cdot 2$ & $0 \cdot 4$ & $0 \cdot 4$ & $0 \cdot 4$ & $0 \cdot 2$ & $0 \cdot 4$ & $0 \cdot 3$ & $0 \cdot 8$ \\
\hline Nutritional supplements & $8 \cdot 8$ & $10 \cdot 3$ & $4 \cdot 4$ & $6 \cdot 7$ & $4 \cdot 1$ & $10 \cdot 5$ & $4 \cdot 0$ & $8 \cdot 1$ \\
\hline Bread \& rolls & $4 \cdot 1$ & 4.4 & $5 \cdot 4$ & $5 \cdot 5$ & $7 \cdot 0$ & $5 \cdot 3$ & $7 \cdot 1$ & $5 \cdot 0$ \\
\hline Other food groups & $25 \cdot 6$ & $32 \cdot 1$ & $25 \cdot 9$ & $30 \cdot 3$ & $27 \cdot 4$ & $33 \cdot 7$ & $33 \cdot 3$ & $30 \cdot 5$ \\
\hline
\end{tabular}

The mean daily intake (MDI) of riboflavin from the total diet was $2.5 \mathrm{mg} / \mathrm{d}$ (ranging from $2 \cdot 2-3 \cdot 1 \mathrm{mg} / \mathrm{d}$ range across population groups) with $18 \%$ having inadequate intakes (10-26\% range across ages). Blood sample analysis showed that $61 \%$ of adults exceeded the EGRac cut-off of $1 \cdot 3$. The key dietary sources of riboflavin in the population were milks (20-24\% across ages), 'meat \& meat products' (14-18\%), ready-to-eat breakfast cereals (6-14\%), 'beverages' (7-12\%) and 'bread \& rolls' (4-7\%). Nutritional supplements provided $4-10 \%$ of intakes. Results were similar when analysis was restricted to those with biochemical data only $(n 1126)$. These findings show that a significant proportion of Irish adults have low dietary intakes of riboflavin. Even higher proportions have evidence of deficient/ low biomarker status; however, the functional significance of an EGRac value $>1.3$ is unclear and requires further research.

This publication has emanated from research supported in part by a Grant from Science Foundation Ireland (Grant number 16/ERA-HDHL/3357) within the programme of ERA-HDHL - Biomarkers for Nutrition \& Health. (www.healthydietforhealthylife.eu/index.php/64-open-calls/311-derive). The National Adult Nutrition Survey was funded by the Irish Department of Agriculture, Fisheries \& Food under the Food for Health Research Initiative (2007-2012).

1. Food Standards Agency (2002) The Composition of Foods. Cambridge: Royal Society of Chemistry

2. Black LJ, Ireland J, Moller A et al. (2011) J Food Compost Anal 24(7), 1017-1023.

3. Tooze JA, Kipnis V, Buckman DW et al. (2010) Stat Med 29(27), 2857-2868.

4. EFSA (2017) EFSA J 15(8), 4919.

5. McAuley E, McNulty H, Huges C et al. (2016) Proc Nutr Soc 75(3), 405-414. 